\title{
Endoscopic biliary drainage as a bridging procedure to single-stage surgery for perforated choledochal cyst: a case report and review of the literature
}

Takuya Minagawa ${ }^{1,4}$, Shoichi Dowaki ${ }^{{ }^{*}}$, Hiroyuki Kikunaga ${ }^{1}$, Koji Fujita $^{1}$, Keiichi Ishikawa ${ }^{1}$, Katsuaki Mori ${ }^{1}$, Tadayuki Sakuragawa' ${ }^{1}$ Shunsuke Ichisaka ${ }^{1}$, Hiroshi Miura ${ }^{2}$, Koichiro Kumai ${ }^{1}$, Shuji Mikami ${ }^{3}$ and Yuko Kitagawa ${ }^{4}$

\begin{abstract}
Choledochal cyst (CC) - a congenital anomaly of the bile duct-is rare. We report a 28-year-old woman complaining of epigastralgia who was transferred to our hospital. Physical examination revealed severe tenderness to abdominal palpation without symptoms of diffuse peritonitis. Urgent contrast-enhanced abdominal computed tomography indicated the dilated common bile duct (CBD) was perforated, with a presumed diagnosis of perforated CC. Endoscopic external biliary drainage was performed immediately as a bridging procedure to the definitive surgery. Additional evaluations confirmed a type IVa CC, according to Todani's classification, but no signs of malignancy. Twenty-two days after biliary drainage, laparotomy was performed. A large cystic mass was found in the CBD with a perforated scar on the right-side wall. Because inflammation around the pancreas head was too severe to perform cyst excision safely, the patient underwent subtotal stomach-preserving pancreatoduodenectomy. The postoperative course was uneventful, and the patient was discharged on the 29th postoperative day. Pathologic examination of a specimen showed no malignancy, and the patient has remained well during the 3-year follow-up. Our experience with this case suggests that definitive single-stage surgery for perforated CC in an adult can be performed safely owing to external biliary drainage as a bridging procedure, if manifestation of diffuse peritonitis is not evident.
\end{abstract}

Keywords: Choledochal cyst, Perforation, Endoscopic biliary drainage, Adult, Single-stage surgery

\section{Background}

Choledochal cyst $(\mathrm{CC})$ in adults is rare [1], but perforation of CC occasionally has been reported following invasive procedures in or around the common bile duct (CBD) or after trauma [2-4]. Spontaneous perforation of $\mathrm{CC}$ is an extremely rare cause of abdominal pain in adults. Patients commonly undergo two-stage surgery comprising urgent peritoneal lavage and T-tube biliary drainage by laparotomy as the first surgery, and cyst excision and biliary reconstruction as the second surgery [5-9]. However, we believe there is a less invasive alternative to laparotomy for biliary drainage in many cases. Because more than $90 \%$ of CCs are associated with

\footnotetext{
* Correspondence: dowaki@biscuit.ocn.ne.jp

'Department of Surgery, Hino Municipal Hospital, 4-3-1 Tamadaira, Hino,

Tokyo 191-0062, Japan

Full list of author information is available at the end of the article
}

anomalous pancreaticobiliary ductal union (APBDU) $[10,11]$, and because biliary ductal carcinoma occasionally is seen in adults with CC [12-14], it is essential to evaluate the bile duct thoroughly before performing the definitive surgery. Here, we report a thought-provoking case of spontaneous perforation of $\mathrm{CC}$ in an adult woman. The patient was successfully managed by endoscopic external biliary drainage followed by complete cyst excision. We also review past cases in the literature and discuss the problems associated with management and timing of the definitive surgery for perforated $\mathrm{CC}$ in adults.

\section{Case presentation}

A 28-year-old woman experienced sudden-onset abdominal pain with associated nausea and vomiting during the night. She was transferred to our hospital complaining of severe epigastralgia. The patient's medical history was 
unremarkable. Her blood pressure was 104/66 mmHg, her heart rate was 107 beats/min, and her body temperature was $37.7{ }^{\circ} \mathrm{C}$. On physical examination, she had severe tenderness to palpation around the umbilicus with no signs of diffuse peritonitis. Laboratory results were as follows: white blood cell count, $13.3 \times 10^{9} / \mathrm{L}$; hemoglobin, $14.6 \mathrm{~g} / \mathrm{dL}$; aspartate aminotransaminase, $623 \mathrm{IU} / \mathrm{L}$; alanine aminotransaminase, $431 \mathrm{IU} / \mathrm{L}$; total bilirubin, $4.9 \mathrm{mg} / \mathrm{dL}$; alkaline phosphatase, 1007 IU/L; gamma-glutamyl transpeptidase, $939 \mathrm{IU} / \mathrm{L}$; and C-reactive protein, $3.7 \mathrm{mg} / \mathrm{dL}$.

Urgent contrast-enhanced abdominal computed tomography $(\mathrm{CT})$ revealed remarkable dilatation of the $\mathrm{CBD}$. It also demonstrated fluid collection around the CBD, mainly in the retroperitoneal space, and suspicion of a perforated cyst wall (Fig. 1a). Endoscopic retrograde cholangiopancreatography (ERCP) was performed for further evaluation and biliary drainage, with a presumed diagnosis of perforated CC. ERCP revealed APBDU and biliary leakage out of the CC (Fig. 1b). The concentration of amylase in the bile was $2040 \mathrm{IU} / \mathrm{L}$. After an endoscopic nasal biliary drainage (ENBD) tube was placed, the general condition of the patient improved. Before the definitive surgery, additional multimodal examinations, including cholangiography taken by the ENBD tube (Fig. 1c), CT, magnetic resonance cholangiopancreatography, ultrasonography, and pathology tests, revealed a congenital type IVa CC, according to Todani's classification [6], but no signs of malignancy.

Twenty-two days after endoscopic biliary drainage, laparotomy was performed. Operative findings showed the bile duct was extremely dilated from the porta hepatis to the lower part of the CBD. A single free perforation site was observed at the right-side wall of the CBD, near the confluence of the cystic duct. The other organs had no evidence of perforation. Because inflammation around the pancreas head was severe, it was difficult to
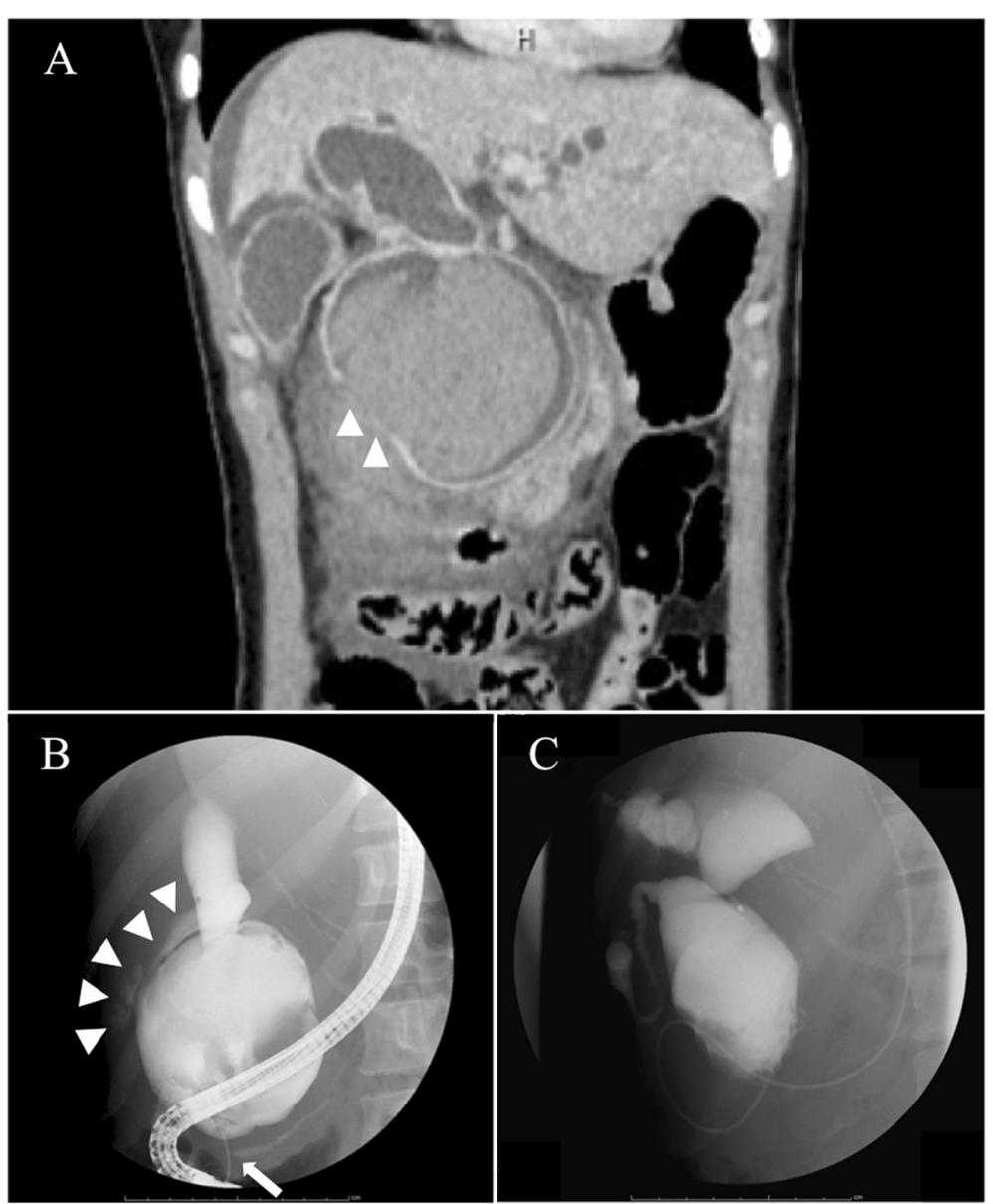

Fig. 1 Preoperative imaging findings. a Urgent contrast-enhanced abdominal computed tomography scan, showing a huge cyst with hemorrhaging in the common bile duct (CBD) and a defect of the contrast medium at the right-side wall of the CBD (arrowheads). Fluid collection around the CBD, mainly in the retroperitoneal space, also is observed. $\mathbf{b}$ Endoscopic retrograde cholangiopancreatogram, showing leakage of the contrast medium from the right-side wall of the dilated CBD (arrowheads) with anomalous pancreaticobiliary ductal union (arrows). c Cholangiogram taken by the nasal biliary drainage tube, showing dilation of both intra- and extrahepatic bile ducts, indicating a type IVa choledochal cyst according to Todani's classification 
dissect the dilated intrapancreatic bile duct safely. For complete resection of the cystic mass, subtotal stomachpreserving pancreatoduodenectomy was performed, and the Traverso technique was employed for reconstruction. The postoperative course was uneventful, and the patient was discharged on the 29th postoperative day. Pathologic examination of a specimen revealed no malignancy, and the patient has remained well during the 3-year follow-up.

\section{Discussion}

$\mathrm{CC}$, or bile duct cyst-a congenital dilation of the biliary tract-is commonly seen in women, East Asians, and children. The incidence of $\mathrm{CC}$ in Western populations ranges from 1 in 100,000 to 1 in 150,000 live births [15], which is thought to be lower than that in Asian countries. In Japan, the total number of admissions to children's hospitals for CC has been estimated to be as high as 1 in 1000 [16], although, it has been reported to be 1 in 13,500 in the USA [17] and 1 in 15,000 in Australia [18]. Biliary cysts can be divided into five subgroups according to Todani's modification of the Alonso-Lej classification [19]. It has been reported that APBDU, which is seen in almost all cases of CC $[10,11]$, predisposes the patient to risk of carcinoma. Incidence of carcinogenesis associated with $\mathrm{CC}$ ranges from $4 \%$ to $30 \%$, and increases with age $[13,14,20-23]$. Given the high risk of malignant conversion, surgical resection of the cyst, especially the extrahepatic bile duct, has been recommended for type IV CCs [23, 24].

Perforation of CC is a rare, but important, condition in children $[25,26]$. Spontaneous perforation of CC in adults is extremely rare $[6,7]$. Surgical management, especially two-stage biliary reconstruction, commonly has been performed for bile peritonitis [5-9]. There are several reasons why two-stage surgery has been strongly recommended. First, the cyst wall is so friable due to severe inflammation that anastomosis in primary closure would be disrupted. This is why T-tube drainage is recommended in the first surgery [27]. Second, because of bile staining and severe inflammation, a definitive procedure can be difficult to perform during emergency exploratory laparotomy. Therefore, it is safer to perform the definitive surgery when the patient recovers from the inflammatory state.

However, in adult cases with no signs of diffuse peritonitis, it might be possible to perform transient biliary drainage using an endoscopic or percutaneous approach. This strategy is not common, but it has several advantages. First, this strategy can be used as a less invasive alternative to emergency drainage by laparotomy for patients in bad general condition. Using endoscopic or percutaneous biliary drainage as a bridging procedure, definitive singlestage surgery can be performed when inflammation has improved and the patient is in better condition. The second advantage is that additional examinations can be performed before the definitive surgery while the patient recovers from the inflammatory state. These examinations could make the preoperative evaluation and diagnosis more precise, including assessment of malignant potential. Endoscopic or intraductal ultrasonography, for example, might be effective for preoperative diagnosis due to their high diagnostic accuracy [28, 29]. Bile cytology also could be helpful for diagnosis. Cholangiography taken by the cyst drainage tube would be extremely helpful to plan the optimal definitive surgery. If any signs of malignancy are indicated, R0 surgery and additional lymphadenectomy should be considered. In our case, owing to biliary drainage, multimodal examinations enabled precise evaluation, and helped to simulate the optimal definitive surgery.

There are some considerations to bear for this strategy. In our case, there were no evident indicators of histologic improvement from the inflammatory state. Rapid recovery from the acute phase and sufficient biliary drainage for almost 3 weeks allowed us to suspect improvement from the inflammatory state. However, the definitive surgery was complicated by residual inflammation around the pancreas head. Therefore, it can be difficult to determine proper timing of the definitive surgery following transient biliary drainage. It is easy to understand that biomarkers of inflammation, such as white blood cell count or serum C-reactive protein level, and patients' symptoms indicate clinical improvement from the inflammatory state. However, these criteria do not always indicate histological improvement. As in the management of other inflammatory diseases, a sufficient interval might be needed for safe operation. An interval appendectomy for acute appendicitis in children is generally planned 2 or 3 months after conservative management [30]. Histological findings suggest that the adhesion around the appendix improves about 2 months after the disappearance of symptoms [31]. On the other hand, early cholecystectomy following biliary drainage for acute cholecystitis is reported to be preferable if the patient's condition improves, because surgery is easy to perform when the inflammation has improved and the adhesion is still soft and fresh [32, 33]. Based on these findings, with regard to histological tissue inflammation, it might be better to plan elective surgery either within $72 \mathrm{~h}$ or over 2 months after the onset of symptoms. However, malignancy might be difficult to rule out within $72 \mathrm{~h}$ after the onset of symptoms. Therefore, in clinical practice, it might be recommended to perform elective surgery over 2 months after the onset and disappearance of symptoms if biliary drainage is carefully managed. Our patient required continuous biliary drainage due to extreme narrowing of the lower biliary tract; therefore, ENBD was thought to be a better intervention for biliary drainage than endoscopic biliary stenting (EBS). This is because 
Table 1 Literature review for spontaneous perforated choledochal cyst in adults

\begin{tabular}{|c|c|c|c|c|c|c|c|c|c|c|c|c|}
\hline $\begin{array}{l}\text { Case } \\
\text { no. [ref.] }\end{array}$ & $\begin{array}{l}\text { Age } \\
\text { (years) } \\
\text { /sex }\end{array}$ & Nationality & $\begin{array}{l}\text { Clinical } \\
\text { presentation }\end{array}$ & $\begin{array}{l}\text { Preoperative } \\
\text { abdominal } \\
\text { paracentesis }\end{array}$ & $\begin{array}{l}\text { Choledochal } \\
\text { cyst (Todani's } \\
\text { classification) }\end{array}$ & $\begin{array}{l}\text { Preoperative } \\
\text { drainage }\end{array}$ & $\begin{array}{l}\text { Approach for } \\
\text { drainage }\end{array}$ & $\begin{array}{l}\text { Surgery } \\
\text { (single- or } \\
\text { two-stage) }\end{array}$ & $\begin{array}{l}\text { The first surgical } \\
\text { procedure }\end{array}$ & $\begin{array}{l}\text { The second surgical } \\
\text { procedure }\end{array}$ & $\begin{array}{l}\text { Interval period } \\
\text { from diagnosis } \\
\text { to definitive } \\
\text { surgery }\end{array}$ & $\begin{array}{l}\text { Postoperative } \\
\text { complications }\end{array}$ \\
\hline \multirow[t]{2}{*}{$1[1]$} & \multirow[t]{2}{*}{$28 / F$} & \multirow[t]{2}{*}{ Korea } & \multirow{2}{*}{$\begin{array}{l}\text { Bile } \\
\text { peritonitis }\end{array}$} & \multirow[t]{2}{*}{$(+)$} & \multirow[t]{2}{*}{$N / D$} & \multirow[t]{2}{*}{$(-)$} & \multirow[t]{2}{*}{ N/A } & \multirow[t]{2}{*}{ Single } & Cyst excision & \multirow[t]{2}{*}{ N/A } & \multirow[t]{2}{*}{ N/D } & \multirow[t]{2}{*}{$\mathrm{N} / \mathrm{D}$} \\
\hline & & & & & & & & & Hepaticojejunostomy & & & \\
\hline \multirow[t]{3}{*}{$2[5]$} & \multirow[t]{3}{*}{ N/D } & \multirow[t]{3}{*}{ India } & \multirow{3}{*}{$\begin{array}{l}\text { Bile } \\
\text { peritonitis }\end{array}$} & \multirow[t]{3}{*}{$(+)$} & \multirow{3}{*}{$\begin{array}{l}\text { Type I or } \\
\text { type IVa }\end{array}$} & \multirow[t]{3}{*}{$(-)$} & \multirow[t]{3}{*}{ N/A } & \multirow[t]{3}{*}{ Two } & \multirow{3}{*}{$\begin{array}{l}\text { T-tube } \\
\text { choledochocystostomy } \\
\text { Peritoneal lavage }\end{array}$} & Cyst excision & \multirow[t]{3}{*}{ 4-8 weeks } & \multirow[t]{3}{*}{ N/D } \\
\hline & & & & & & & & & & \multirow{2}{*}{ Hepaticojejunostomy } & & \\
\hline & & & & & & & & & & & & \\
\hline \multirow[t]{3}{*}{$3[5]$} & \multirow[t]{3}{*}{ N/D } & \multirow[t]{3}{*}{ India } & \multirow{3}{*}{$\begin{array}{l}\text { Bile } \\
\text { peritonitis }\end{array}$} & $(+)$ & Type I or & $(-)$ & N/A & Two & T-tube & Cyst excision & 4-8 weeks & N/D \\
\hline & & & & & type IVa & & & & choledochocystostomy & Hepaticojejunostomy & & \\
\hline & & & & & & & & & Peritoneal lavage & & & \\
\hline $4[5]$ & N/D & India & Localized & $(+)$ & Type I or & $(+)$ & Percutaneous & Single & Cyst excision & N/A & 4-8 weeks & N/D \\
\hline & & & & & type IVa & & & & Hepaticojejunostomy & & & \\
\hline $5[6]$ & $24 / \mathrm{M}$ & Greece & & $(-)$ & Type IVa & $(-)$ & N/A & Two & T-tube & Cyst excision & N/D & N/D \\
\hline & & & peritonitis & & & & & & choledochocystostomy & Hepaticojejunostomy & & \\
\hline & & & & & & & & & Peritoneal lavage & & & \\
\hline $6[7]$ & $25 / \mathrm{M}$ & Greece & & $(-)$ & Type IVa & $(-)$ & N/A & Two & T-tube & Cyst excision & 8-12 weeks & SSI \\
\hline & & & peritonitis & & & & & & choledochocystostomy & Hepaticojejunostomy & & \\
\hline & & & & & & & & & Peritoneal lavage & & & \\
\hline $7[26]$ & $24 / F$ & Korea & Bile & $(-)$ & Type I & $(+)$ & Percutaneous & Single & Cyst excision & N/A & 1 week & None \\
\hline & & & peritonitis & & & & & & Hepaticojejunostomy & & & \\
\hline $8[8]$ & $28 / F$ & India & Bile & $(+)$ & Type I & $(-)$ & N/A & Two & T-tube & Cyst excision & 12 weeks & N/D \\
\hline & & & & & & & & & choledocnocystostomy & Hepaticojejunostomy & & \\
\hline & & & & & & & & & Peritoneal lavage & & & \\
\hline 9 [9] & $25 / F$ & India & Bile & N/D & N/D & $(-)$ & N/A & Two & T-tube & Cyst excision & N/D & $\mathrm{N} / \mathrm{D}$ \\
\hline & & & & & & & & & choledochocystostomy & Hepaticojejunostomy & & \\
\hline & & & & & & & & & Peritoneal lavage & & & \\
\hline $10[27]$ & $18 / F$ & Canada & Bile & $(+)$ & Type I & $(+)$ & Percutaneous & Single & Cyst excision & N/A & 8 weeks & None \\
\hline & & & pe & & & & $1+5$ & & Hepaticojejunostomy & & & \\
\hline $\begin{array}{l}\text { Present } \\
\text { case }\end{array}$ & $28 / F$ & Japan & $\begin{array}{l}\text { Bile } \\
\text { peritonitis }\end{array}$ & $(-)$ & Type IVa & $(+)$ & Endoscopic & Single & SSPPD & N/A & 3 weeks & None \\
\hline
\end{tabular}

$F$ female, $M$ male, N/A not applicable, N/D not described, SSI surgical site infection, SSPPD subtotal stomach preserving pancreatoduodenectomy 
ENBD can detect nonfunctioning of the biliary drainage system much earlier and because exchanging an ENBD tube for an EBS tube might be a challenging procedure with a high risk of re-perforation in this case. Our patient could not wait more than 2 months for elective surgery because of social issues; therefore, she underwent definitive surgery 3 weeks after the onset of symptoms.

If malignancy is suspected, endoscopic biliary drainage might be performed using a percutaneous approach with regard to peritoneal dissemination. Both endoscopic and percutaneous approaches are appropriate for biliary drainage near the CBD. On the other hand, it would be better to employ a percutaneous approach when bile collection is distant from the bile duct. If necessary, a combination of these approaches can be considered for better management.

In a PubMed database search, we found 10 cases in eight English articles addressing management of spontaneously perforated CC in adults $[1,5-9,34,35]$. We summarize the features and clinical course of these 10 cases in Table 1. In most of these cases, patients were aged in their twenties, from East or South Asian countries, and presented with bile peritonitis. All 10 cases were either a type I or IVa CC, according to Todani's classification, and had no signs of malignancy. Preoperative abdominal paracentesis confirmed biliary leakage in six cases. Two-stage surgery comprising T-tube choledochocystostomy and peritoneal lavage as the first surgery, and cyst excision and hepaticojejunostomy as the second surgery was performed in six cases. Single-stage surgery was performed in the other four cases; preoperative percutaneous biliary drainage was performed in three of them. The interval from diagnosis to definite surgery varied from case to case. Almost all of the cases managed by two-stage surgery might have been treated by single-stage surgery with preoperative biliary drainage, if they had no manifestation of diffuse peritonitis. Although it is difficult to clearly define the criteria for single-stage surgery for perforated CC, the lack of clinical signs of diffuse peritonitis or malignancy at initial assessment might be helpful factors for planning this elective surgery. It is controversial whether to plan single-stage or two-stage surgery. However, if the clinical outcomes for both strategies are the same, single-stage surgery would be better because it is potentially more cost-effective and safe. In addition to the two advantages described above, elective surgery when the patient's condition has improved can have better results and avoid a possible emergency operation.

\section{Conclusions}

We experienced a successfully managed case of perforated $\mathrm{CC}$ in an adult who underwent endoscopic biliary drainage followed by a definitive single-stage surgery. This strategy has potential benefits in the management of patients without diffuse peritonitis or evidence of malignancy. It is difficult, but important, to determine proper timing of the definitive surgery. Long-term follow-up is also necessary because postoperative neoplastic change has been reported [36, 37].

\section{Consent}

Written informed consent was obtained from the patient for publication of this case report and any accompanying images. A copy of the written consent is available for review by the Editor-in-Chief of this journal.

\section{Abbreviations}

APBDU: anomalous pancreaticobiliary ductal union; CBD: common bile duct; CC: choledochal cyst; CT: computed tomography; EBS: endoscopic biliary stenting; ENBD: endoscopic nasal biliary drainage; ERCP: endoscopic retrograde cholangiopancreatography.

\section{Competing interests}

The authors declare that they have no competing interests.

\section{Authors' contributions}

TM wrote the manuscript. SD participated in the surgery, and supervised the writing of the manuscript. HK, KF, KI, KM, TS, and SI prepared the data from the reviewed articles. HM prepared the radiologic findings. KK represents our hospital, and supervised the writing of the manuscript. MS analyzed the pathologic specimens. YK represents our surgical department, and supervised the writing of the manuscript. All authors significantly contributed to this study and approved the final manuscript.

\section{Author details}

'Department of Surgery, Hino Municipal Hospital, 4-3-1 Tamadaira, Hino, Tokyo 191-0062, Japan. ${ }^{2}$ Department of Radiology, Hino Municipal Hospital, 4-3-1 Tamadaira, Hino, Tokyo 191-0062, Japan. ${ }^{3}$ Division of Diagnostic Pathology, Keio University Hospital, 35 Shinanomachi, Shinjuku-ku, Tokyo 160-8582, Japan. ${ }^{4}$ Department of Surgery, Keio University School of Medicine, 35 Shinanomachi, Shinjuku-ku, Tokyo 160-8582, Japan.

Received: 16 June 2015 Accepted: 28 October 2015

Published online: 17 November 2015

\section{References}

1. Kang SB, Han HS, Min SK, Lee HK. Nontraumatic perforation of the bile duct in adults. Arch Surg. 2004;139:1083-7.

2. Kumar A. Spontaneous perforation of the common bile duct: a rare cause of acute abdomen in adults. Surgery. 1998;124:924-5.

3. Raj JP, Walsh M. Choledochal cyst and blunt trauma-case report. Injury. 2002;33:644-6.

4. Duan YF, Yang B, Zhu F. Traumatic rupture of a type IVa choledochal cyst in an adult male. World J Gastroenterol. 2013;19:3911-4.

5. Lal R, Agarwal S, Shivhare R, Kumar A, Sikora SS, Kapoor VK, et al. Management of complicated choledochal cysts. Dig Surg. 2007;24:456-62.

6. Stipsanelli E, Valsamaki P, Tsiouris S, Arka A, Papathanasiou G, Ptohis N, et al. Spontaneous rupture of a type IVA choledochal cyst in a young adult during radiological imaging. World J Gastroenterol. 2006;12:982-6.

7. Fragulidis GP, Marinis AD, Anastasopoulos GV, Vasilikostas GK, Koutoulidis V. Management of a ruptured bile duct cyst. J Hepatobiliary Pancreat Surg. 2007:14:194-6.

8. Joseph P, Raju RS, Vyas FL, Sitaram V. Spontaneous perforation of choledochal cyst and hyperemesis gravidarum. Trop Gastroenterol. 2008;29:46-7.

9. Singh H, Gupta R, Dhaliwal L, Singh R. Spontaneous choledochal cyst perforation in pregnancy with co-existent chronic pancreatitis. BMJ Case Rep. 2014. doi:10.1136/bcr-2014-207183.

10. Wang HP, Wu MS, Lin CC, Chang LY, Kao AW, Wang HH, et al. Pancreaticobiliary diseases associated with anomalous pancreaticobiliary ductal union. Gastrointest Endosc. 1998;48:184-9.

11. Komi N, Tamura T, Miyoshi Y, Kunitomo K, Udaka H, Takehara H. Nationwide survey of cases of choledochal cyst. Analysis of coexistent anomalies, 
complications and surgical treatment in 645 cases. Surg Gastroenterol. 1984;3:69-73.

12. Visser BC, Suh I, Way LW, Kang SM. Congenital choledochal cysts in adults. Arch Surg. 2004;139:855-60.

13. Lee KF, Lai EC, Lai PB. Adult choledochal cyst. Asian J Surg. 2005;28:29-33.

14. Huang CS, Huang CC, Chen DF. Choledochal cysts: differences between pediatric and adult patients. J Gastrointest Surg. 2010;14:1105-10.

15. Singham J, Yoshida EM, Scudamore CH. Choledochal cysts: part 1 of 3 : classification and pathogenesis. Can J Surg. 2009;52:434-40.

16. Kimura K, Tsugawa C, Ogawa K, Matsumoto Y, Yamamoto T, Kubo M, et al. Choledochal cyst. Etiological considerations and surgical management in 22 cases. Arch Surg. 1978;113:159-63.

17. Hays DM, Goodman GN, Snyder Jr WH, Woolley MM. Congenital cystic dilatation of the common bile duct. Arch Surg. 1969;98:457-61.

18. Jones PG, Smith ED, Clarke AM, Kent M. Choledochal cysts: experience with radical excision. J Pediatr Surg. 1971;6:112-20.

19. Todani T, Watanabe Y, Narusue M, Tabuchi K, Okajima K. Congenital bile duct cysts: classification, operative procedures, and review of thirty-seven cases including cancer arising from choledochal cyst. Am J Surg. 1977;134:263-9.

20. Liu CL, Fan ST, Lo CM, Lam CM, Poon RT, Wong J. Choledochal cysts in adults. Arch Surg. 2002;137:465-8.

21. Jan YY, Chen HM, Chen MF. Malignancy in choledochal cysts. Hepatogastroenterology. 2002:49:100-3.

22. Bloustein PA. Association of carcinoma with congenital cystic conditions of the liver and bile ducts. Am J Gastroenterol. 1977:67:40-6.

23. Kobayashi S, Ohnuma N, Yoshida H, Ohtsuka Y, Terui K, Asano T, et al. Preferable operative age of choledochal dilation types to prevent patients with pancreaticobiliary maljunction from developing biliary tract carcinogenesis. Surgery. 2006;139:33-8.

24. Shah OJ, Shera AH, Zargar SH, Shah P, Robbani I, Dhar S, et al. Choledocha cysts in children and adults with contrasting profiles: 11-year experience at a tertiary care center in Kashmir. World J Surg. 2009:33:2403-11.

25. Chiang L, Chui CH, Low Y, Jacobsen AS. Perforation: a rare complication of choledochal cysts in children. Pediatr Surg Int. 2011;27:823-7.

26. Goel P, Jain V, Manchanda V, Sengar M, Gupta CR, Mohta A. Spontaneous biliary perforations: an uncommon yet important entity in children. J Clin Diagn Res. 2013;7:1201-6.

27. Ando H, Ito T, Watanabe Y, Seo T, Kaneko K, Nagaya M. Spontaneous perforation of choledochal cyst. J Am Coll Surg. 1995;181:125-8.

28. Zaheer A, Anwar MM, Donohoe C, O'Keeffe S, Mushtaq H, Kelleher B, et al The diagnostic accuracy of endoscopic ultrasound in suspected biliary obstruction and its impact on endoscopic retrograde cholangiopancreatography burden in real clinical practice: a consecutive analysis. Eur J Gastroenterol Hepatol. 2013;25:850-7.

29. Meister T, Heinzow HS, Woestmeyer C, Lenz P, Menzel J, Kucharzik T, et al Intraductal ultrasound substantiates diagnostics of bile duct strictures of uncertain etiology. World J Gastroenterol. 2013;19:874-81.

30. Gillick J, Velayudham M, Puri P. Conservative management of appendix mass in children. Br J Surg. 2001:88:1539-42.

31. Otake S, Suzuki N, Takahashi A, Toki F, Nishi A, Yamamoto H, et al. Histological analysis of appendices removed during interval appendectomy after conservative management of pediatric patients with acute appendicitis with an inflammatory mass or abscess. Surg Today. 2014;44:1400-5.

32. Chikamori F, Kuniyoshi N, Shibuya N, Takase Y. Early scheduled laparoscopic cholecystectomy following percutaneous transhepatic gallbladder biliary drainage for patients with acute cholecystitis. Surg Endosc. 2002;16:1704-7.

33. Yamashita Y, Takada T, Strasberg SM, Pitt HA, Gouma DJ, Garden OJ, et al. TG 13 surgical management of acute cholecystitis. J Hepatobiliary Pancreat Sci. 2013;20:89-96.

34. Kang CM, Lee KH, Kim DH, Lee WJ. Percutaneous transhepatic cyst drainage as a "bridge procedure" to definitive treatment of perforated choledochal cysts: a case report. Surg Laparosc Endosc Percutan Tech. 2008;18:598-600.

35. Meschino M, García-Ochoa C, Hernandes-Alejandro R. Ruptured choledochal cyst: a rare presentation and unique approach to management. Hepatobiliary Surg Nutr. 2015;4:E8-E12.

36. Kobayashi S, Asano T, Yamasaki M, Kenmochi T, Nakagohri T, Ochiai T. Risk of bile duct carcinogenesis after excision of extrahepatic bile ducts in pancreaticobiliary maljunction. Surgery. 1999;126:939-44.

37. Ohashi T, Wakai T, Kubota M, Matsuda Y, Arai Y, Ohyama T, et al. Risk of subsequent biliary malignancy in patients undergoing cyst excision for congenital choledochal cysts. J Gastroenterol Hepatol. 2013;28:243-7.

\section{Submit your manuscript to a SpringerOpen ${ }^{\circ}$ journal and benefit from:}

- Convenient online submission

- Rigorous peer review

- Immediate publication on acceptance

- Open access: articles freely available online

- High visibility within the field

- Retaining the copyright to your article

Submit your next manuscript at $>$ springeropen.com 